\title{
Tes Tertulis Berbasis HOTS pada Pembelajaran IPA Menggunakan Google Form Siswa Kelas IV SD
}

\author{
Gede Weda Baskara ${ }^{1}{ }^{*}$, Ndara Tanggu Renda ${ }^{2}$, Kadek Yudiana ${ }^{3}$
}

1,2,3 Program Studi Pendidikan Guru Sekolah Dasar, Universitas Pendidikan Ganesha, Singaraja, Indonesia

\section{A R T I C L E I N F O}

Article history:

Received September 06, 2021

Revised September 09, 2021

Accepted September 29, 2021

Available online October 25, 2021

Kata Kunci:

Instrumen HOTS, IPA, Google Form

Keywords:

HOTS Instruments, IPA, Google Form

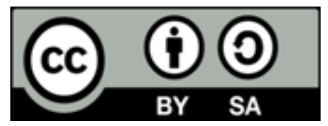

This is an open access article under the CC BY-SA license.

Copyright $(\subset) 2021$ by Author. Published by Universitas Pendidikan Ganesha.

\section{A B S T R A K}

Masih banyak guru belum mampu mengembangkan perangkat pembelajaran, sehingga menyebabkan penyusunan instrumen penilaian masih kurang relevan. Selain itu, penekanan tingkat kognitif yang masih sebagian besar berada pada level kognitif rendah. Penelitian ini bertujuan untuk menciptakan instrument tes tertulis berbasis HOTS pada pembelajaran IPA menggunakan google form siswa kelas IV SD. Jenis penelitian ini adalah penelitian pengembangan. Model yang digunakan pada penelitian ini yaitu menggunakan model $A D D I E$. Teknik yang digunakan dalam mengumpulkan data yaitu observasi, wawancara, pencatatan dokumen, dan tes. Instrument yang digunakan dalam mengumpulkan data yaitu kuesioner. Subjek dalam penelitian ini menggunakan 2 ahli dosen dan uji coba menggunakan 60 orang siswa. Hasil penelitian akan dianalisis validitas dan reliabilitas, menunjukkan jumlah butir soal yang valid sebanyak 25 butir dan yang tidak valid sebanyak 5 butir. Setelah itu dilakukan uji reabilitas, Pada uji reliabilitas ini dapat dilakukan jika butir soal dinyatakan valid. Reliabilitas instrument dapat diuji menggunakan rumus Kuder Richardson 20 (KR-20) dengan bantuan aplikasi Microsoft Office Excel. Hasil perhitungan reliabilitas instrument 30 butir soal diperoleh $r_{11}=0,76$ memiliki reliabilitas yang "Tinggi". Maka, instrument tes tertulis berbasis HOTS pada pembelajaran IPA menggunakan google form siswa kelas IV SD valid dan layak digunakan sebagai instrumen penilaian hasil belajar siswa. Implikasi penelitian ini yaitu instrumen tes tertulis berbasis HOTS menggunakan google form yang dikembangkan ini dapat digunakan oleh guru untuk mengukur pemahaman siswa selama mengikuti proses pembelajaran.

\section{A B S TR A C T}

There are still many teachers who have not been able to develop learning tools. The preparation of assessment instruments is still less relevant because it relies on instruments provided from the center. The emphasis on the cognitive level is still mostly on the low cognitive level. This study aims to develop a written test instrument based on HOTS in science learning using google form for fourth grade elementary school students. This type of research is development research. The model used in this study is using the ADDIE (analyze), (design), (development), (implementation), (evaluation) model. The techniques used in collecting data are observation, interviews, document recording, tests. The instrument used in collecting data is a questionnaire. The research results will be analyzed for validity and reliability. Instruments that have been designed to collect data are then tested first in order to find out the validity of the instrument. The results showed that the number of valid items was 25 items and the invalid items were 5 items. After that, a reliability test is carried out. In this reliability test, it can be done if the items are declared valid. Instrument reliability can be tested using the Kuder Richardson 20 (KR-20) formula with the help of Microsoft Office Excel application. The results of the calculation of the reliability of the instrument 30 items obtained $r 11=0.76$ has a "High" reliability. So, the HOTS-based written test instrument in science learning using the Google Form for fourth grade elementary school students is valid and feasible to be used as an instrument for assessing student learning outcomes. The implication of this research is that the HOTS-based written test instrument using the developed google form can be used by teachers to measure students' understanding during the learning process. 


\section{PENDAHULUAN}

Pembelajaran adalah proses interaksi peserta didik dengan pendidik. Pembelajaran dikatakan berhasil jika tujuan pembelajaran dapat tercapai secara maksimal. Pembelajaran harus dapat melibatkan seluruh peserta didik agar ikut berperan aktif pada kegiatan pembelajaran yang dilaksanakan, sehingga nantinya dapat merubah sikap atau prilaku siswa menjadi lebih baik (Tegeh \& Kirna, 2013; Wahyu \& Ambros Leonangung Edu, 2020). Tujuan pembelajaran akan tercapai dengan baik apabila guru dapat menciptakan suasana pembelajaran yang baik. Pembelajaran akan menjadi menyenangkan jika siswa termotivasi dalam belajar (Dewi, 2018; Suprihatin, 2016). Di Sekolah Dasar siswa mendapatkan beberapa muatan mata pelajar salah satunya adalah muatan pembelajaran IPA. Pembelajaran IPA di Sekolah Dasar merupakan pondasi awal untuk menciptakan siswa yang memiliki pengetahuan, keterampilan dan sikap ilmiah (Agustina, 2015; Halim, 2017). Mata pelajaran IPA bertujuan agar siswa memahami alam dan mampu memecahkan masalah yang mereka jumpai di sekitar. Sehingga hasil belajar yang didapatkan bisa dijadikan cerminan dalam kemampuan pengetahuan serta pemahaman konsep siswa. Untuk mengukur pengetahuan dan pemahaman siswa perlu dilakukan penilaian. Penilaian merupakan kegiatan penyetandaran hasil belajar siswa melalui kegiatan asesmen dan evaluasi (Vijayaratnam, 2012; Widiana, 2016). Penilaian merupakan proses mengumpulkan serta mengolah informasi untuk mengukur pencapaian hasil belajar peserta didik (Chng \& Lund, 2018; Wicaksono et al., 2016; Zuliani et al., 2017). Pencapaian hasil belajar berupa kognitif, afektif dan psikomotorik. Guru memiliki peran penting dalam melatih kemampuan berpikir siswa (Dewi, 2018; Mega et al., 2015; Mulyadin, 2016). Proses penilaian mencakup penilaian otentik, penilaian diri, penilaian berbasis portofolio, ulangan, ulangan harian, ulangan tengah semester, ulangan akhir semester, ujian tingkat kompetensi, ujian mutu tingkat kompetensi, ujian nasional, dan ujian sekolah/madrasah (Salamah, 2018; Subagia \& Wiratma, 2016). Suatu penilaian dikatakan baik apabila memenuhi prinsip-prinsip penilaian. Prinsip penilaian meliputi objektif, terpadu, ekonomis, transparan, akuntabel dan edukatif (Subagia \& Wiratma, 2016).

Namun permasalahan yang terjadi saat ini yaitu masih banyak guru yang kesulitan membuat instrument penilaian belajar siswa (Arif, 2016; Pratiwi, 2017; Sadiyyah et al., 2019). Permasalahan lain yaitu guru tidak menggunakan instrumen penilaian melainkan hanya mengamati kegiatan pembelajaran untuk mengumpulkan data (Mundia Sari \& Setiawan, 2020; Primasari et al., 2020). Selain itu masih banyak guru belum mampu mengembangkan perangkat pembelajaran (Nugroho, 2018; Wirdaningsih et al., 2017). Berdasarkan hasil wawancara melalui media sosial (Whatsapp) dengan guru-guru di sekolah dasar gugus III Kecamatan Bangli terkait mata pelajaran IPA pada kelas IV, diperoleh beberapa informasi terkait kendala yang ada di sekolah dasar tersebut, yaitu penyusunan instrumen penilaian masih kurang relevan karena mengandalkan instrument yang disediakan dari pusat. Penekanan tingkat kognitif yang masih sebagian besar berada pada level kognitif rendah yaitu pada tingkatan mengingat dan memahami yaitu C1 dan C2. Proses penilaian pembelajaran, guru memerlukan waktu ynag cukup lama karena kondisi pembelajaran daring, menyebabkan terdapat beberapa siswa yang menjawab tepat waktu dan ada yang menjawab di lain waktu. Pembuatan soal evaluasi yang kurang menyesuaikan dengan kopetensi dasar. Hal ini sangat perlu diperhatikan agar memberikan penilaian yang tepat terhadap sejauh mana siswa memahami materi pembelajaran IPA. Apabila masalah ini tidak segera diatasi akan memberikan dampak negatif bagi kualitas pendidikan.

Solusi yang dapat dilakukan untuk mengatasi permasalahan tersebut yaitu dengan mengembangkan instrument tes tertulis berbasis HOTS pada Pembelajaran IPA Menggunakan Google Form. Upaya yang dapat dilakukan guru yaitu dapat guru dapat memberikan tes berbasis HOTS untuk melatih siswa. Tes berbasis Higher Order Thinking Skill (HOTS) dapat membantu siswa mengembangkan kemampuan berpikir (Andoko, 2020; Ineson et al., 2013; Pratiwi, 2017; Saraswati \& Agustika, 2020). Higher Order Thinking Skills adalah kemampuan peserta didik yang berfikir secara kritis, berfikir kreatif, kemampuan berargumen dan kemampuan berani mengambil keputusan (Anwar et al., 2020; Roets \& Jeanette Maritz, 2017; Sani, 2019; Seibert, 2020). Sehubungan dengan hal tersebut proses pembelajaran HOTS sulit dikembangkan di era pandemic ini, karena pembelajar dilakukan secara daring. Maka dari itu untuk mengembangkan soal HOTS perlu menggunakan google form. Google Form merupakan aplikasi yang mudah digunakan bahkan bagi para pemula karena tidak menggunakan koding untuk pembuatanya (Rahmiyanti, 2019). Google form dapat digunakan untuk melakukan kuis online, survei tentang efektifitas pengajaran, mengumpulkan jawaban pertanyaan terbuka dan sebagainya (Permata \& Bhakti, 2020; Santosa et al., 2020).

Temuan penelitian sebelumnya menyatakan bahwa asesmen HOTS layak diterapkan untuk siswa sekolah dasar (Saraswati \& Agustika, 2020). Temuan lain menyatakan bahwa soal berbasis HOTS sangat penting dilakukan untuk mengukur ketercapaian pembelajaran (Kwangmuang et al., 2021; Prastikawati et al., 2021; Umami et al., 2021). Permbelajaran menggunakan google form lebih efiktif dilakukak pada masa pandemi covid19 (An et al., 2019; Anwar et al., 2020). Perbedan penelitian ini dengan penelitian sebelumnya yaitu penelitian sebelumnya hanya mengembangkan instrumen hasil belajar berbasis HOTS, sedangkan pada penelitian ini mengembangkan instrumen hasil belajar berbasis HOTS pada pembelajaran IPA menggunakan google form. Belum adanya kajian yang mendalam mengenai instrument tes tertulis hasil belajar IPA berbasis Higher Order Thinking Skills menggunakan google form Penelitian ini bertujuan untuk menciptakan instrument berbasis hots 
pada pembelajaran ipa menggunakan google form siswa kelas IV SD. Adanya instrumen Tes tertulis berbasis HOTS pada Pembelajaran IPA Menggunakan Google Form dapat membantu siswa dalam mengembangkan kemampuan berpikir tingkat tinggi. Selain itu instrumen ini disajikan menggunakan google form sehingga guru dapat menggunakan instrumen ini dalam pembelajaran daring selama pandemi covid-19.

\section{METODE}

Penelitian ini berjenis pengembangan. Penelitian pengembangan adalah penelitian yang digunakan untuk mengembangkan suatu produk dan menguji keefektifan produk tersebut. Dalam penelitian pengembangan ini dirancang menggunakan model ADDIE (analyze), (design), (development), (implementation), (evaluation). Tahap analisis (analysis) adalah menganalisis topik pembelajaran dan kebutuhan siswa. Dilanjutkan dengan taahap perencanaan (design) pada tahap ini adalah tahapan untuk membuat rancangan yang berupa kisi-kisi intrumen penilaian. Kemudian, tahap pengembangan (devlopment) adalah mewujudkan rancangan yang sudah disusun berupa kisi-kisi instrument penilaian menjadi butir soal. Selanjutnya, tahap implementasi (implementation) adalah tahapan untuk mengimplementasikan rancangan yang telah disusun berupa kisi-kisi intrumen dan dikembangkan menjadi butir soal, dan yang terakhir tahap evaluasi (evaluation) adalah sebuah proses yang dilakukan untuk memberikan nilai terhadap pengembangan bahan ajar dalam pembelajaran. Secara lebih spesifik tahapan model ADDIE ini akan dijabarkan pada gambar 1.

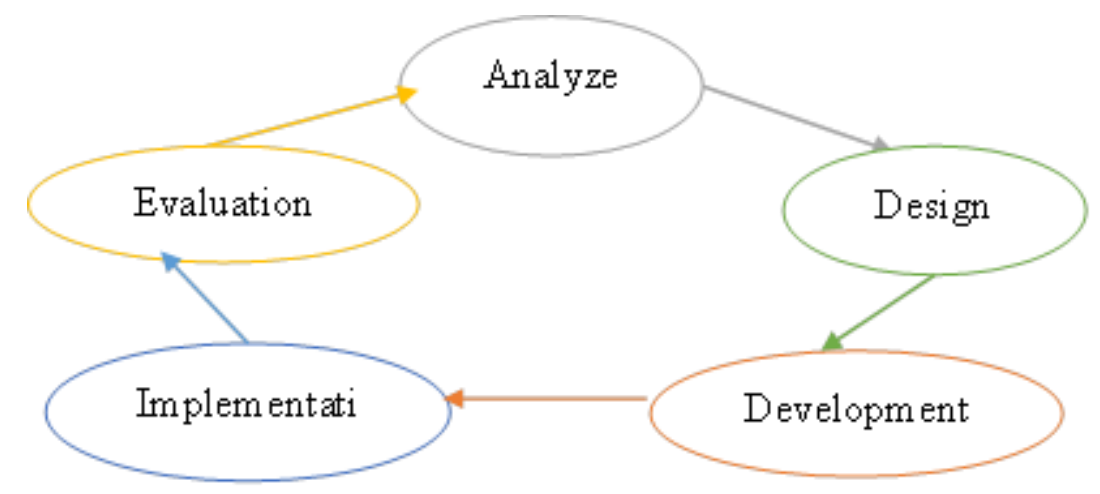

Gambar 1. Model ADDIE (Tegeh et al., 2014)

Subjek penelitian yaitu instrument penilaian hasil belajar IPA pada kelas IV Semester Ganjil di Gugus III Kecamatan Bangli, yang diajukan kepada 2 ahli/pakar dalam bidang pembelajaran IPA dan uji coba dilakukan kepada 60 orang siswa kelas IV. Metode pengumpulan data dalam penelitian ini adalah dengan menggunakan metode tes. Tes yang digunakan berupa tes objektif pilihan ganda. Dengan begitu data yang dikumpulkan adalah data hasil validitas instrument hasil belajar IPA. Instrument yang digunakan dalam penelitian ini adalah tes hasil belajar IPA yang disusun dalam bentuk tes pilhan ganda. Dengan tes hasil belajar diharapkan siswa dapat mengungkapkan hasil belajar terhadap materi pembelajaran untuk ranah pengetahuan (kognitif). Hasil penelitian akan dianalisis validitas dan reliabilitas. Instrumen yang telah dirancang untuk mengumpulkan data selanjutnya diuji coba terlebih dahulu agar mengetahui kevalidan instrumen. Instrument penelitian dianalisis dengan menggunakan uji validitas isi dan uji validitas butir tes. Uji validitas isi dilakukan menggunakan rumus Gregory. Validitas butir empiric yang dipilih adalah rumus Kuder Richardson 20 (KR-20). Uji reliabilitas juga dilakukan untuk mengukur validitas tes.

\section{HASIL DAN PEMBAHASAN}

\section{Hasil}

Pada penelitian ini, model yng digunakan yaitu model ADDIE yang terdiri dari 5 tahapan yaitu analyze, design, development, implementation, evaluation. Pertama yaitu analisis, tahap analyze (analisis) adalah menganalisis topik pembelajaran dan kebutuhan siswa. Analisis kebutuhan pada penelitian menggunakan instrument yang dapat mengevaluasi siswa dalam proses pembelajaran di Gugus III Kecamatan Bangli yang telah terlaksana melalui tahapan observasi dan wawancara secara daring untuk memperoleh permasalahan dalam penelitian. Selanjutnya menganalisis topik pembelajaran dengan cara menganalisis hasil belajar yang telah dijelaskan oleh guru secara daring untuk mengetahui kopetensi dasar dan indicator pencapain, serta tujuan pembelajaran untuk membuat instrument penelitian yang relevan dalam topik ini. Tahap kedua, dilanjutkan dengan tahap design (perencanaan) pada tahap ini adalah tahapan untuk membuat rancangan yang berupa kisikisi instrument penilaian. Adapun kisi-kisi kuesioner tersaji pada tabel 1. 
Tabel 1. Kisi-kisi Instrumen Penilaian

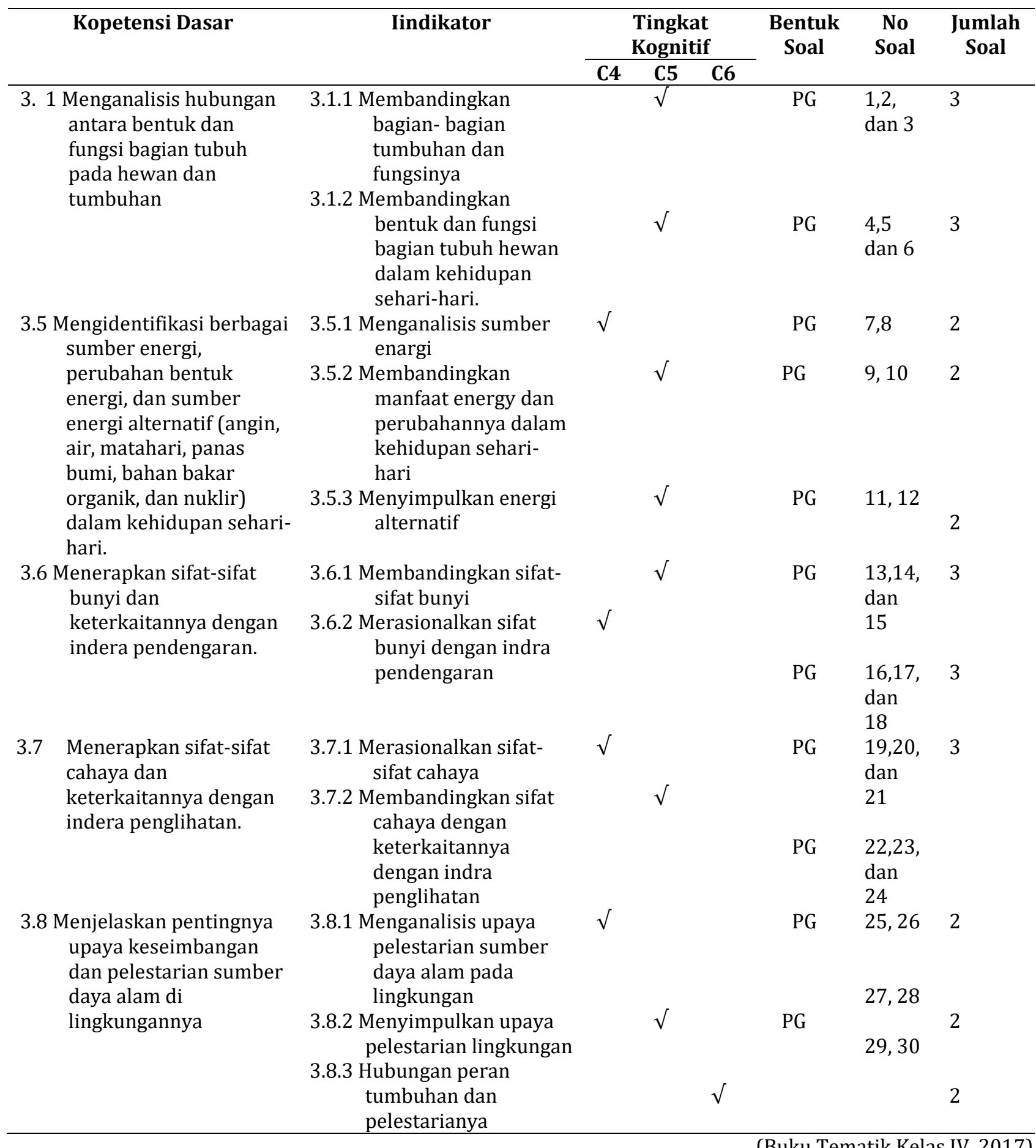

Kemudian, tahap development (pengembangan) mewujudkan rancangan yang sudah di susun berupa kisi-kisi instrument penilaian menjadi butir soal. tahapan Development (pengembangan), yang dilaksanakan melalui kegiatan pengembangan instrument penilaian pada semester ganjil di kelas IV Gugus III Kecamatan bangli yang telah dikonsultaksikan kepada dosen pembimbing untuk memperbaiki kekurangan yang ada pada instrument yang telah dibuat. Setelah melakukan perbaikan pada instrument, dilanjutkan untuk uji ahli/pakar pada instrument agar mengetahui instrument ini relevan atau tidak. Kemudian dilaksanakan dengan memberikan lembar penilaian validitas instrument kepada pakar dalam bidang muatan IPA meliputi dua orang dosen untuk menguji instrument itu relevan kemudian diuji cobakan kepada siswa di Gugus III Kecamatan Bangli. Adapun hasil dari uji ahli disajikan pada tabel 2. Berdasarkan tabel 2. diketahui bahwa dari 29 pertanyaan yang dikembangkan dinyatakan relevan. Sebanyak 1 pertanyaan tidak relevan. Berdasarkan hasil perhitungan, indeks validitas isi instrument tersebut adalah 0,96. Jika dikonvensikan, maka instrumen hasil belajar IPA yang diujikan berada pada kriteria "Sangat Tinggi". Selanjutnya dilakukan uji coba validitas butir 
soal dilakukan pada siswa kelas IV di Gugus III Kecamatan Bangli. Tes yang di uji cobakan berjumlah 30 butir soal pilihan ganda yang diujikan dengan 60 orang siswa di Gugus III Kecamatan Bangli. Data hasil uji validitas butir dianalisis menggunakan rumus korelasi Biserial yang dibantu dengan aplikasi Microsoft Office Exel.

Tabel 2. Hasil Uji Ahli

\begin{tabular}{cccc}
\hline Ahli I & \multicolumn{2}{c}{ Ahli II } \\
\hline Relevan & Tidak Relevan & Relevan & Tidak Relevan \\
\hline $1,2,3,4,5,6,7,8,9,10,11,12,13,14,15$, & - & $1,2,4,5,6,7,8,9,10,11,13$, & 12 \\
$16,17,18,19,20,21,22,23,24,25,26$, & & $14,15,16,17,18,19,20,21$, & \\
$27,28,29,30$ & & $22,23,24,25,26,27,28,29,30$ & \\
\hline
\end{tabular}

Uji coba yang dilakukan dengan siswa di Gugus III Kecamatan Bangli, sebanyak 60 orang siswa untuk mengetahu validitas tiap butir soal. Suatu butir soal dikatakan valid apabila $r$ hitung $>r$ tabel. Dengan menggunakan taraf singnifikan 5\% yaitu $r$ tabel $=0,254$. Berdasarkan analisis data, didapatkan bahwa jumlah butir soal yang valid sebanyak 25 butir dan yang tidak valid sebanyak 5 butir. Setelah itu dilakukan uji reabilitas, Pada uji reliabilitas ini dapat dilakukan jika butir soal dinyatakan valid. Reliabilitas instrument dapat diuji menggunakan rumus Kuder Richardson 20 (KR-20) dengan bantuan aplikasi Microsoft Office Excel. Hasil perhitungan reliabilitas instrument 30 butir soal diperoleh $\mathrm{r}_{11}=0,76$ memiliki reliabilitas yang “Tinggi". Selanjutnya, tahap implementation (impelementasi) yaitu tahap yang seharusnya mengimplementasikan rancangan yang telah di susun berupa kisi-kisi instrument dan dikembangkan menjadi butir soal tidak dilaksanakan karena situasi dan kondisi Covid-19 yang tidak memungkinkan dan keterbatasan waktu. Terakhir yaitu tahap evaluasi adalah sebuah proses yang dilakukan untuk memberikan nilai terhadap pengembangan bahan ajar dalam pembelajaranjuga tidak dapat telaksana, dikarenakan situasi Covid-19 serta keterbatasan waktu dalam penelitian pengembangan ini.

Berdasarkan hasil analisis data, maka instrument yang penilaian tes tertulis berbasis HOTS pada pembelajaran IPA menggunakan google form valid dan layak digunakan sebagai instrumen penilaian IPA pada siswa. Instrument hasil belajar IPA berbasis Higher Order Thinking menggunakan google form valid dan layak digunakan disebabkan oleh beberapa faktor yaitu sebagai berikut. Pertama, instrumen layak digunakan karena sudah memenuhi persyaratan instrument penilaian yang baik dan benar. Instrumen yang baik adalah instrumen yang memenuhi persyaratan sehingga instrumen yang dikembangkan berkualitas (Gaol et al., 2017; Zuliani et al., 2017). Syarat instrument penilaian yang paling utama yaitu valid, reabilitas, dan praktis. Instrument yang baik dan layak digunakan harus memiliki kevaliditas dan reliabilitas (Arif, 2016; Seibert, 2020; Solihah et al., 2020; Yusup, 2018). Pengembangan instrument yang dilakukan sudah melalui uji ahli dan melakukan revisi instrumen sesuai saran dan masukan dari para ahli sehingga instrument tes yang dikembangkan menjadi berkualitas. Kedua, instrument tes tertulis berbasis HOTS pada pembelajaran IPA menggunakan google form valid dan layak digunakan disebabkan instrument ini dapat diakses dimanapun dan kapan pun. Google Form adalah aplikasi yang mudah digunakan untuk menyebarkan angket atau kuisioner secara cepat dimanapun ia berada dengan menggunakan aplikasi internet (Anwar et al., 2020; Permata \& Bhakti, 2020). Penilaian pada pembelajaran dapat dilakukan melalui tes. Adanya tes bertujuan untuk mengukur pemahaman siswa (Adjii, 2019; Gaol et al., 2017; Yusup, 2018). Untuk mencapai tujuan tersebut, maka setiap butir tes harus disusun sesuai dengan tujuan pembelajaran dan memiliki tingkat berpikir yang tinggi (HOTS). Pada penelitian ini instrument tes tulis berbasis HOTS memiliki kriteria validitas dan reliabilitas yang sangat tinggi. Berdasarkan hasil yang didapatkan, instrumen hasil belajar memiliki validitas dan reliabilitas yang berada pada kriteria sangat tinggi. Sehingga instrumen ini layak digunakan sebagai alat evaluasi pada pembelajaran IPA.

Temuan penelitian ini diperkuat dengan penelitian sebelumnya yang menyatakan instrumen berbasis HOTS dapat meningkatkan kemampuan berpikir tingkat tinggi siswa (Anwar et al., 2020; Nisa et al., 2018; Umami et al., 2021). Menyatakan bahwa instrument tes yang baik dapat mengukur higher order thinking skill pada siswa (Umami et al., 2021). Penelitian lain menciptakan instrumen berbasis HOTS pada pembelajaran matematika yang diberikan kepada siswa secara langsung (Ndiung \& Jediut, 2020; Saraswati \& Agustika, 2020). Selain itu, temuan lain terkait instrumen berbasis HOTS menggunakan e-quiz (electronic quiz) untuk sekolah dasar layak diterapkan (Aini \& Sulistyani, 2020). Berdasarkan hasil pembahasan tes tertulis berbasis HOTS pada pembelajaran IPA menggunakan google form dapat digunakan pada proses evaluasi pembelajaran. instrumen yang diciptakan memiliki kelebihan yaitu sudah melewati uji validitas dan reliabilitas, selain itu instumen ini berbasis HOTS dan di sajikan menggunakan google form. Namun penelitian ini memiliki keterbatasan yaitu hanya dilakukan sampai tahap pengembangan, tahap implementasi dan evaluasi tidak dapat dilaksanakan karena keterbatan adanya pandemi covid-19. Diharapkan penelitian selanjutnya dapat melanjutkan penelitian pengembangan ini melalui penelitian eksperimen. Implikasi penelitian ini yaitu instrumen tes tertulis berbasis HOTS menggunakan google form yang dikembangkan ini dapat digunakan oleh guru untuk mengukur pemahaman siswa selama mengikuti proses pembelajaran. penelitianini memberikan kontribusi bagi guru guru 
dalam memahami cara pembuatan soal yang baik, sehingga tujuan pembelajaran dapat tercapai dengan maksimal.

\section{SIMPULAN}

Berdasarkan hasil analisis data yang diperoleh instrument tes tertulis berbasis HOTS pada pembelajaran IPA menggunakan google form telah memenuhi kriteria valid, reliael, dan memiliki kualitas yang baik. Dapat disimpulkan bahwa instrument tes tertulis berbasis HOTS pada pembelajaran IPA menggunakan google form valid dan layak digunakan sebagai instrumen penilaian pada siswa.

\section{DAFTAR PUSTAKA}

Adjii, K. (2019). Instrumen penilaian kedisiplinan siswa sekolah menengah kejuruan. Assessment and Research on Education, 1(1). https://doi.org/10.33292/arisen.v1i1.19.

Agustina, R. L. (2015). Upaya Meningkatkan Hasil Belajar IPA Siswa Kelas IV Menggunakan Model STAD dan NHT. Journal of Educational Science and Technology (EST), 1 (3). https://doi.org/10.26858/est.v1i3.1801.

Aini, D. F. N., \& Sulistyani, N. (2020). Pengembangan Instrumen Penilaian E-Quiz (Electronic Quiz) Matematika Berbasis HOTS (HIGHER OF ORDER THINKING SKILLS) untuk Kelas V Sekolah Dasar. Jurnal Pendidikan Dan Pembelajaran Sekolah Dasar, 7(2), 1-11. https://doi.org/10.21107/widyagogik.v7i2.5980.

An, K., Imania, N., \& Bariah, S. K. (2019). Rancangan pengembangan instrumen penilaian pembelajaran berbasis daring. 5, 31-47. https://doi.org/10.31980/jpetik.v5i1.445.

Andoko. (2020). Peningkatan Hots Dan Prestasi Belajar Melalui Metode Inkuiri Kelas 7C SMPN 1 Wonosobo Tahun Pelajaran 2018/2019. Spektra: Jurnal Kajian Pendidikan Sains, 6(1). https://doi.org/10.32699/spektra.v6i1.134.

Anwar, Y., Selamet, A., Huzaifah, S., \& Madang, K. (2020). Training in developing higher-order thinking based online test instrument for biology teachers in Sekayu City. Journal of Community Service and Empowerment, 1(3), 150-155. https://doi.org/10.22219/jcse.v1i3.12241.

Arif, M. (2016). Pengembangan Instrumen Penilaian Mapel Sains melalui Pendekatan Keterampilan Proses Sains SD/MI. Ta'allum: Jurnal Pendidikan Islam, 4(1). https://doi.org/10.21274/taalum.2016.4.1.123-148.

Chng, L. S., \& Lund, J. (2018). Assessment for learning in physical education: the what, why and how. Journal of Physical Education, Recreation and Dance, 89(8), 29-34. https://doi.org/10.1080/07303084.2018.1503119.

Dewi, R. S. (2018). Kemampuan Profesional Guru Dan Motivasi Kerja Terhadap Kinerja Mengajar Guru Sekolah Dasar. Jurnal Administrasi Pendidikan, 25(1), 150-158. https://doi.org/10.17509/jap.v25i1.11581.

Gaol, P. L., Khumaedi, M., \& Masrukan, M. (2017). Pengembangan Instrumen Penilaian Karakter Percaya Diri pada Mata Pelajaran Matematika Sekolah Menengah Pertama. Journal of Research and Educational Research Evaluation, 6(1). https://doi.org/10.15294/jrer.v6i1.16209.

Halim, D. (2017). Pengembangan Video Pembelajaran IPA Pada Materi Pencemaran Dan Kerusakan Lingkungan. Jurnal Pendidikan Sains Indonesia, 5(2), 108-114. https://doi.org/10.24815/jpsi.v5i2.9825.

Ineson, E. M., Jung, T., Hains, C., \& Kim, M. (2013). The influence of prior subject knowledge, prior ability and work experience on self-efficacy. Journal of Hospitality, Leisure, Sport and Tourism Education, 12(1), 59-69. https://doi.org/10.1016/j.jhlste.2012.11.002.

Kwangmuang, P., Jarutkamolpong, S., Sangboonraung, W., \& Daungtod, S. (2021). The development of learning innovation to enhance higher order thinking skills for students in Thailand junior high schools. Heliyon, 7(6). https://doi.org/10.1016/j.heliyon.2021.e07309.

Mega, C., Pudjawan, K., \& Margunayasa, I. G. (2015). Analisis sikap sosial siswa kelas V pada pembelajaran dengan kurikulum 2013. Mimbar PGSD Universitas Pendidikan Ganesha, 3(1). https://doi.org/10.23887/jjpgsd.v3i1.5631.

Mulyadin. (2016). Implementasi Kebijakan Pembelajaran Tematik Terpadu Kurikulum 2013 di SDN Kauman 1 Malang dan SD Muhammadiyah 1 Malang. Jurnal Pendidikan Edutama, 3(2), 31-48. https://doi.org/10.30734/jpe.v3i2.35.

Mundia Sari, K., \& Setiawan, H. (2020). Kompetensi Pedagogik Guru dalam Melaksanakan Penilaian Pembelajaran Anak Usia Dini. Jurnal Obsesi: Jurnal Pendidikan Anak Usia Dini, 4(2), 900. https://doi.org/10.31004/obsesi.v4i2.478.

Ndiung, S., \& Jediut, M. (2020). Pengembangan instrumen tes hasil belajar matematika peserta didik sekolah dasar berorientasi pada berpikir tingkat tinggi. Premiere Educandum: Jurnal Pendidikan Dasar Dan Pembelajaran, 10(1), 94. https://doi.org/10.25273/pe.v10i1.6274.

Nisa, N. A. K., Widyastuti, R., \& Hamid, A. (2018). Pengembangan Instrumen Assesment Higher Order Thinking Skill (HOTS) Pada Lembar Kerja Peserta Didik Kelas VII SMP. Prosiding Seminar Nasional Matematika Dan Pendidikan 
http://www.ejournal.radenintan.ac.id/index.php/pspm/article/view/2465.

Nugroho, R. (2018). Pengembangan Perangkat Pembelajaran Dengan Pendekatan Contextual Teaching And Learning Untuk Meningkatkan Motivasi Dan Hasil Belajar Bagi Siswa Kelas Iv Sekolah Dasar. Jurnal Bidang Pendidikan Dasar, 2(2). https://doi.org/10.21067/jbpd.v2i2.2638.

Permata, A., \& Bhakti, Y. B. (2020). Keefektifan Virtual Class dengan Google Classroom dalam Pembelajaran Fisika Dimasa Pandemi Covid-19. JIPFRI (Jurnal Inovasi Pendidikan Fisika Dan Riset Ilmiah), 4(1), 27-33. https://doi.org/10.30599/jipfri.v4i1.669.

Phawani Vijayaratnam. (2012). Developing Higher Order Thinking Skills and Team Commitment via Group Problem Solving: A Bridge to the Real World. Procedia - Social and Behavioral Sciences, 66, 53-63. https://doi.org/10.1016/j.sbspro.2012.11.247.

Prastikawati, E. F., Wiyaka, W., \& Budiman, T. C. S. (2021). Pelatihan Penyusunan Soal Bahasa Inggris Berbasis HOTS bagi Guru Bahasa Inggris SMP. Jurnal Pengabdian Masyarakat, 6(1). https://doi.org/10.30653/002.202161.761.

Pratiwi, P. H. (2017). Pengembangan Modul Mata Kuliah Penilaian Pembelajaran Sosiologi Berorientasi HOTS. Cakrawala Pendidikan, 36(2). https://doi.org/10.21831/cp.v36i2.13123.

Primasari, I. F. N. D., Marini, A., \& Sumantri, M. S. (2020). Analisis Kebijakan Dan Pengelolaan Pendidikan Terkait Standar Penilaian Di Sekolah Dasar. Jurnal Basicedu, 3(2), 524-532. https://doi.org/10.31004/basicedu.v5i3.956.

Roets, L., \& Jeanette Maritz. (2017). Facilitating the development of higher-order thinking skills (HOTS) of novice nursing postgraduates in Africa. Nurse Education Today, 47, 51-56. https://doi.org/10.1016/j.nedt.2016.11.005.

Sadiyyah, R., Gustiana, M., Panuluh, S. D., \& Sugiarni, R. (2019). Pengembangan Lembar Kerja Siswa (LKS) dengan Pendekatan Inkuiri Terbimbing Berbasis Mobile Learning untuk Mengoptimalkan Kemampuan Berpikir Kritis Matematis. PRISMA, 8(1), 80. https://doi.org/10.35194/jp.v8i1.616.

Salamah, U. (2018). Penjaminan Mutu Penilaian Pendidikan. Evaluasi (Jurnal Manajemen Pendidikan Islam), 372(2), 2499-2508. https://doi.org/10.32478/evaluasi.v2i1.79.

Sani, R. A. (2019). Pembelajaran Berbasis HOTS Edisi Revisi: Higher Order Thinking Skills. Tira Smart.

Santosa, F. H., Negara, H. R. P., \& Samsul Bahri. (2020). Efektivitas Pembelajaran Google Classroom Terhadap Kemampuan Penalaran Matematis Siswa. Jurnal Pemikiran Dan Penelitian Pendidikan Matematika (JP3M), 3(1), 62-70. https://doi.org/10.36765/jp3m.v3i1.254.

Saraswati, P. M. S., \& Agustika, G. N. S. (2020). Kemampuan Berpikir Tingkat Tinggi Dalam Menyelesaikan Soal HOTS Mata Pelajaran Matematika. Jurnal Ilmiah Sekolah Dasar Undiksha, 4(2). https://doi.org/10.23887/jisd.v4i2.25336.

Seibert, S. A. (2020). Problem-based learning: A strategy to foster generation Z's critical thinking and perseverance. Teaching and Learning in Nursing, 000, 2-5. https://doi.org/10.1016/j.teln.2020.09.002.

Solihah, A. N., Jubaedah, Y., \& Rifa'i, M. S. S. (2020). Pengembangan Instrumen Pengukuran Perkembangan SosialEmosional Anak Berbasis Home-Based Childcare. Widyadari, 6(1). https://doi.org/10.5281/zenodo.3517997.

Subagia, I. W., \& Wiratma, I. G. L. (2016). Profil Penilaian Hasil Belajar Siswa Berdasarkan Kurikulum 2013. JPI (Jurnal Pendidikan Indonesia), 5(1), 39-54. https://doi.org/10.23887/jpi-undiksha.v5i1.8293.

Suprihatin, S. (2016). Upaya guru dalam meningkatkan motivasi belajar siswa. Jurnal Pendidikan Ekonomi UM Metro, 3(1), 72-82. https://doi.org/10.24127/ja.v3i1.144.

Tegeh, I. M., Jampel, I. N., \& Pudjawan, K. (2014). Model Penelitian Pengembangan. Graha Ilmu.

Tegeh, I. M., \& Kirna, I. M. (2013). Pengembangan Bahan Ajar Metode Penelitian Pendidikan dengan ADDIE Model. Jurnal Pendidikan, 11(1), 16. https://doi.org/10.23887/ika.v11i1.1145.

Umami, R., Rusdi, M., \& Kamid, K. (2021). Pengembangan Instrumen Tes Untuk Mengukur Higher Order Thinking Skills (Hots) Berorientasi Programme For International Student Asessment (Pisa) Pada Peserta Didik. JP3M: Jurnal Penelitian Pendidikan Dan Pengajaran Matematika, 7(1). https://doi.org/10.37058/jp3m.v7i1.2069.

Wahyu, Y., \& Ambros Leonangung Edu, M. N. (2020). Problematika Pemanfaatan Media Pembelajaran IPA di Sekolah Dasar. Jurnal Penelitian Pendidikan IPA, 6(1), 107-112. https://doi.org/10.29303/jppipa.v6i1.344.

Wicaksono, T. P., Muhardjito, \& Harsiati, T. (2016). Pengembangan penilaian sikap dengan teknik observasi , self assessment, dan peer assessment pada pembelajaran tematik kelas V SDN Arjowinangun 02 Malang. Jurnal Pendidikan: Teori, Penelitian, Dan Pengembangan, 1(1), 45-51. https: //doi.org/10.17977/jp.v1i2.5214.

Widiana, I. W. (2016). Pengembangan Asesmen Proyek Dalam Pembelajaran IPA di Sekolah Dasar. JPI (Jurnal Pendidikan Indonesia), 5(2), 147. https://doi.org/10.23887/jpi-undiksha.v5i2.8154.

Wirdaningsih, S., Arnawa, I. M., \& Anhar, A. (2017). Pengembangan Perangkat Pembelajaran Matematika Dengan Pendekatan Contextual Teaching And Learning Untuk Meningkatkan Kemampuan Pemecahan Masalah Peserta Didik Kelas XI. Jurna Nasional Pendidikan Matematika, 1(2). https://doi.org/10.33603/jnpm.v1i2.535. 
Yusup, F. (2018). Uji Validitas dan Reliabilitas Instrumen Penelitian Kuantitatif. Jurnal Tarbiyah : Jurnal Ilmiah Kependidikan, 7(1), 17-23. https://doi.org/10.18592/tarbiyah.v7i1.2100.

Zuliani, D., Florentinus, T. S., \& Ridlo, S. (2017). Pengembangan Instrumen Penilaian Karakter pada Siswa Kelas IV Sekolah Dasar. Journal of Research and Educational Research Evaluation, 6(1). https://doi.org/10.15294/jrer.v6i1.16207. 